Primljen / Received: 23.12.2011

Ispravljen / Corrected: 3.4.2012

Prihvaćen / Accepted: 10.4.2012

Dostupno online / Available online: 25.4.2012.

\title{
Analytical procedure for determining critical load of plates under variable boundary conditions
}

Authors:

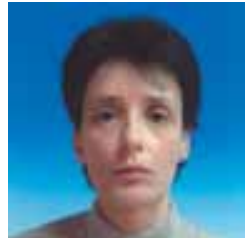

Assistant Prof. Olga Mijušković, PhD. CE University of Monte Negro

Faculty of Civil Engineering in Podgorica olja64@yahoo.com

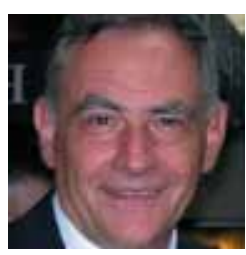

Prof. Branislav Ćorić, PhD. CE

University of Belgrad

Faculty of Civil Engineering

bcoric@grf.bg.ac.rs
Olga Mijušković, Branislav Ćorić

Original scientific paper

Analytical procedure for determining critical load of plates with variable boundary conditions

An analytical procedure for determining critical load, exerted on rectangular plates subjected to arbitrary external load under variable boundary conditions, is presented in the paper. The procedure used in critical load determination is based on the Ritz energy method. Because of complexity of mathematical model used, the case of locally distributed compressive stress is analyzed. The applicability and high level of accuracy of the method presented in the paper is proven through comparison of buckling coefficients and analysis results. This comparison is made using examples of plates with variable boundary conditions.

Key words:

elastic stability of plates, accurate stress function, combined boundary conditions, local load

Izvorni znanstveni rad

Olga Mijušković, Branislav Ćorić

Analitički postupak odredivanja kritičnog opterećenja ploča različitih rubnih uvjeta

U radu je predstavljen analitički postupak za određivanje kritičnog opterećenja pravokutnih ploča različitih rubnih uvjeta pod djelovanjem proizvoljnog vanjskog opterećenja. Postupak određivanja kritičnog opterećenja temeljen je na Ritz-ovoj energijskoj metodi. S obzirom na složenost matematičkog modela, analiziran je slučaj lokalno raspodijeljenog tlačnog naprezanja. Na primjerima ploča različitih rubnih uvjeta, dokazana je primjenljivost i visoka točnost prikazane metode usporedbom koeficijenata izbočenja s rezultatima proračuna.

Ključne riječi:

elastična stabilnost ploča, točna funkcija naprezanja, mješoviti rubni uvjeti, lokalno opterećenje elastic

Wissenschaftlicher Originalbeitrag

Olga Mijušković, Branislav Ćorić

Analytisches Verfahren zur Feststellung der kritischen Belastung von Blechen mit verschiedenen Randbedingungen

In der Arbeit ist das analytische Verfahren zur Feststellung der kritischen Belastung von rechteckigen Blechen mit verschiedenen Randbedingungen unter der Wirkung von willkürlichen Außenbelastungen dargestellt. Das Verfahren zur Feststellung der kritischen Belastung basiert auf der Ritzschen Energiemethode. Hinsichtlich der Komplexität des mathematischen Modells wurde der Fall der lokal verteilten Druckbeanspruchung analysiert. Anhand von Beispielen von Blechen mit verschiedenen Randbedingungen, wurde die Anwendbarkeit und hohe Präzision der dargestellten Methode durch Vergleich der Knickkoeffizienten mit den Berechnungsresultaten aufgezeigt.

Schlüsselwörter:

Elastische Stabilität von Blechen, exakte Funktionsbeanspruchung, kombinierte Randbedingungen, Lokalbelastung 


\section{Introduction}

The analytical procedure for determining the exact distribution of stress within a rectangular plate loaded in its own plane, which constitutes the basis of this paper, is based on the solution dating back to the 19th century. In fact, already in 1890 Mathieu [1] was the first to determine the function of stress for the concrete case of a rectangular plate loaded along the contour by an arbitrary compressive stress through superposition of two, the so called basic types of load (DEA and DEB), cf. Figure 1.
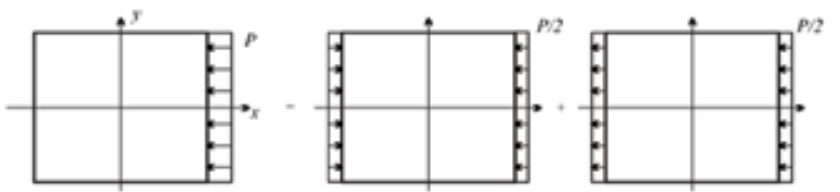

Figure 1. Division of load into cases of DEA and DEB

One of these cases (DEA) was used in the series of papers by Baker and Pavlovic [2-5] during stability analysis of simply supported plates subjected to locally distributed compressive stress. However, several years later [6], more that a century after the original paper published by Mathieu, the same authors turned back to the basic problem, in order to find solution to the exact distribution of stress for a general case of a rectangular plate subjected to arbitrary external load. The essence lies in the fact that any load (normal and/or shear load) acting along the plate contour can be described by selected functions (odd and/ or even with respect to coordinate axes), so that an overall solution is obtained by an appropriate combination of eight basic cases (Figure 2).

To enable a detailed description of the analytical procedure proposed in the paper, we will concentrate on the first basic case of load (DEA) in our analysis of plate behaviour at various edge conditions. According to literature, namely papers by Pavlović and Liu [7], only the examples of simply supported plates with different dimensions to deflection functions ratios, in form of double sine trigonometric series, have so far been analyzed, and they have shown a high level of adaptability to the real buckling pattern.

However, similar analyses have not as yet been made for plates with different boundary conditions. Considering that highly complex forms of external load occur in real-life steel structures, with exact stress distribution patterns, it is also highly significant to check whether the proposed functions properly describe different forms of buckling under any of the above mentioned basic forms of load. In this way, a high accuracy of results can be obtained during description of complex external influences, through superposition of two or more basic types of load.

\section{Theoretical basis of the problem}

Before resolving the selected case of load (DEA), it is indispensable to examine basic Mathieu's expressions based on in-plane elasticity equations, as his analysis and designations / marks partly differ from present-day approaches. In his paper, Mathieu expressed known equilibrium equations, without the action of volume forces, through displacements in form of:

$$
\begin{array}{ll}
\frac{\partial \sigma_{x}}{\partial x}+\frac{\partial \tau_{x y}}{\partial y}=0 & \Delta u=-\frac{1}{\varepsilon} \frac{d v}{d x} \\
\frac{\partial \tau_{y x}}{\partial x}+\frac{\partial \sigma_{y}}{\partial y}=0 & \text { Mathieu } \Rightarrow \quad \Delta v=-\frac{1}{\varepsilon} \frac{d v}{d y}
\end{array}
$$

where

$\Delta \quad$ - Laplaceov operator

$u, v$ - displacements in the direction of $x$ and $y$ $v=\frac{\partial u}{\partial x}+\frac{\partial v}{\partial y}$ - volume dilatation (change in volume)

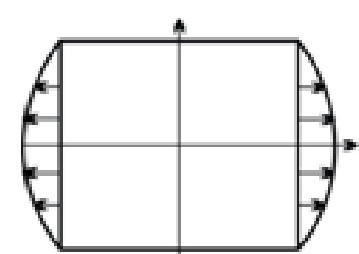

DEA

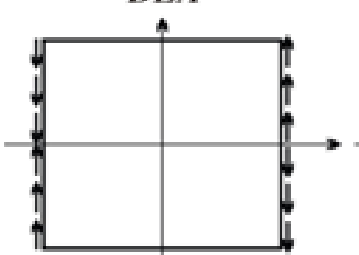

SOA

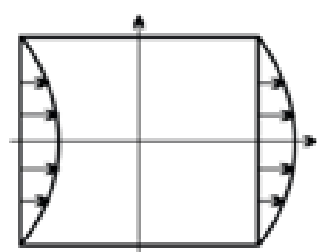

$D E B$

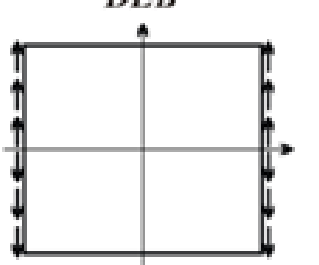

SOR

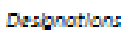

D-normalstres: S-sheorstexs

5-symmetrywth react to $x a x$ 0 - art/somm etry w/th respext tox oxis A-smmetry with espect to y oxds $B$ - antsom metry wth respoct to y oxd:

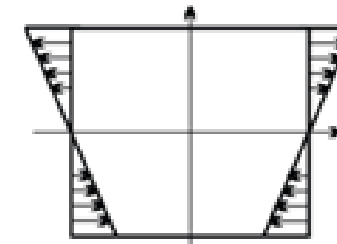

$D O A$

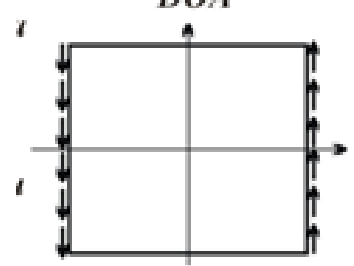

SEA

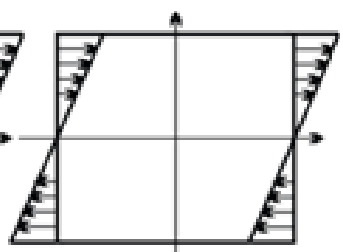

$D O B$

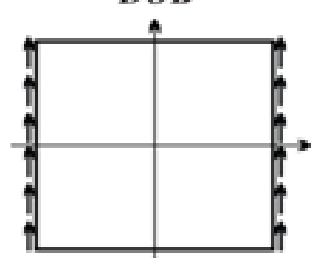

SER

Figure 2. Eight basic types of load 
$\varepsilon=\frac{\mu}{\lambda+\mu} \quad$ - constant defined by Lame coefficients.

Using relatively simple mathematical operations, the equations from system (1) can be written as follows:

$\Delta v=0$

The Mathieu's approach to solving the problem of the plane elasticity theory starts by careful selection of functions for the value $v(4)$ in form of two Fourier series with unknown coefficients, by which the symmetry and antisymmetry of stress distribution has to be described in relation to $x$ and $y$ axes, respectively.

$v=v_{1}+v$

In the next step, the function $F\left(F_{1}+F_{2}\right)$ is introduced based on the requirement that the following equation must be complied with:

$$
\begin{aligned}
& \Delta F=-\frac{1}{\varepsilon} v \quad \Longrightarrow \quad \Delta F_{1}=-\frac{1}{\varepsilon} v_{1} \\
& \Delta F_{2}=-\frac{1}{\varepsilon} v_{2}
\end{aligned}
$$

Finally, once the displacements $u$ and $v$, are defined:

$u=\frac{d F}{d x}+\alpha \int v_{1} d x$

$v=\frac{d F}{d y}+\alpha \int v_{2} d y$

where:

$\alpha=\frac{(\lambda+2 \mu)}{\mu}-$ constant expressed with Lamé parameters

Normal stresses $\mathrm{N}_{1}$ and $\mathrm{N}_{2}$ along $\mathrm{x}$ and $\mathrm{y}$ axes, and the shear stress $\mathrm{T}_{3}$ in the $\mathrm{x}-\mathrm{y}$ plane, are also defined.

$$
\begin{aligned}
& N_{1}=\lambda v+2 \mu \alpha v_{1}+2 \mu \frac{d^{2} F}{d x^{2}} \\
& N_{2}=\lambda v+2 \mu \alpha v_{2}+2 \mu \frac{d^{2} F}{d y^{2}} \\
& T_{3}=\mu\left[2 \frac{d^{2} F}{d x d y}+\alpha \int \frac{d v_{1}}{d y} d x+\alpha \int \frac{d v_{2}}{d x} d y\right]
\end{aligned}
$$

The best and the simplest way to adequately explain the Mathieu's procedure is to analyze in detail one basic type of load (DEA) and to give appropriate explanations and comments.

\section{Exact stress function under variable compressive stress (DEA)}

The computation starts by introducing the external load expression in form of a Fourier series:

$$
f(y)=A_{0}+\sum_{n} A_{n} \cos n y
$$

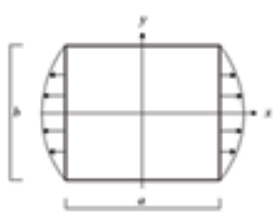

as the DEA case is characterized by symmetry with respect to both axes. In addition, the selection of functions for components $v_{1}$ and $v_{2}$ is contingent upon existence of double symmetry.

$v_{1}=B_{0}+\sum_{n} B_{n} \cosh (n x) \cos n y \quad n=\frac{2 q \pi}{b} \quad q=1,2,3, \ldots$

$v_{2}=\beta_{0}+\sum_{m} \beta_{m} \cosh (m y) \cos m x \quad m=\frac{2 p \pi}{a} \quad \mathrm{p}=1,2,3, \ldots$

Just like the dilatation is shown by superposition of two functions, the value $F$ is also divided into components $F_{1}$ and $F_{2^{\prime}}$ which are the solution to the partial differential equation (6).

$$
\begin{aligned}
F_{1}= & -\frac{1}{2 \varepsilon} B_{0} x^{2}-\frac{1}{2 \varepsilon} \sum_{n} \frac{1}{n} B_{n} x e(n x) \cos n y \\
& +\sum_{n} H_{n} E(n x) \cos n y \\
F_{2}= & -\frac{1}{2 \varepsilon} \beta_{0} y^{2}-\frac{1}{2 \varepsilon} \sum_{m} \frac{1}{m} \beta_{m} y e(m y) \cos m x \\
& +\sum_{m} G_{m} E(m y) \cos m x
\end{aligned}
$$

To enable shorter writing of very complex expressions, appropriate abbreviations are introduced (e.g. $E(\cdot)=\cosh (\cdot)$, or $e(\cdot)=\sinh (\cdot))$ Their meaning will be explained in the course of the derivation.

And finally, by introducing the functions $F_{1}$ and $F_{2}$ into expressions for stress (8), the solution of the problem is reduced to determination of four unknown groups of coefficients $B_{n^{\prime}}$ $\beta_{m^{\prime}} H_{n}$ and $G$ from available boundary conditions. There are in principle eight conditions (two on each contour) for the case of rectangular plate, but they are reduced to indispensable four, because of properties of the introduced dilatation functions. In the DEA example, these are:

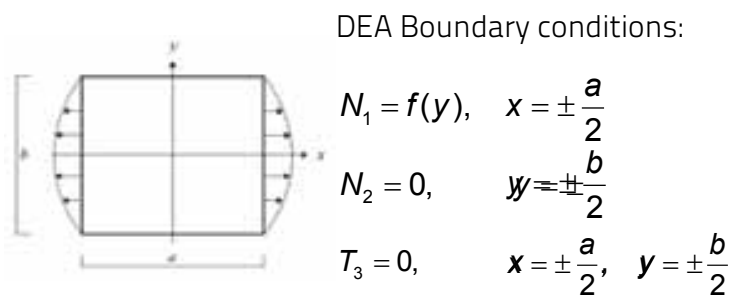

Thus, the solving procedure continues with selection of two boundary conditions by which the direct dependence between appropriate groups of unknown coefficients is defined, while 
the remaining two reduce the problem to an infinite system of linear equations which contain parameters of external load. By using the original Mathieu procedure for solving this problem, the group of coefficients $H_{n}$ and $G_{m}$ can be defined provided that shear stress values at the contour are equal to zero (11c).

$$
\begin{aligned}
& H_{n}=B_{n}\left[-\frac{1}{2 n^{2}}+\frac{a}{4 n \varepsilon} \frac{E\left(\frac{1}{2} n a\right)}{e\left(\frac{1}{2} n a\right)}\right] \\
& G_{m}=\beta_{m}\left[-\frac{1}{2 m^{2}}+\frac{b}{4 m \varepsilon} \frac{E\left(\frac{1}{2} m b\right)}{e\left(\frac{1}{2} m b\right)}\right]
\end{aligned}
$$

The second group of boundary conditions, which is related to distribution of normal stresses, leads the definition of the equation system towards unknown coefficients $B_{n}$ and $\beta_{m^{\prime}}$ which unambiguously define the displacement components and the change in stress within the plate for the analyzed case of load.

$$
\begin{aligned}
& B_{n}=\frac{A_{n}}{(\lambda+\mu) \tau\left(\frac{1}{2} n a\right)}-\frac{8 n^{2} \cos \frac{1}{2} n b}{b \tau\left(\frac{1}{2} n a\right)} \sum_{m} \beta_{m} \frac{m e\left(\frac{1}{2} m b\right) \cos \frac{1}{2} m a}{\left(m^{2}+n^{2}\right)^{2}} \\
& \beta_{m}=-\frac{8 m^{2} \cos \frac{1}{2} m a}{a \tau\left(\frac{1}{2} m b\right)} \sum_{n} B_{n} \frac{n e\left(\frac{1}{2} n a\right) \cos \frac{1}{2} n b}{\left(m^{2}+n^{2}\right)^{2}}
\end{aligned}
$$

The dependence between values $B_{n}$ and $\beta_{m^{\prime}}$ and between external load parameters, is defined in these expressions. And finally, an infinite system of equations (14) is obtained by replacing in the expression $\beta_{m}$ with $B_{n}$ and vice versa, and by multiple introduction of appropriate sums, their combinations of positions, and by reduction to dimensionless form. Naturally, in practical examples we are forced to introduce a finite number of members in a series, and this number must be defined very carefully from the standpoint of convergence and accuracy.

$$
\begin{aligned}
B_{q} & =\frac{A_{q}}{(\lambda+\mu) \tau(q \pi \varphi)}+\frac{16 \varphi^{4} q^{2}(-1)^{q}}{(\lambda+\mu) \pi^{2} \tau(q \pi \varphi)} \sum_{q^{\prime}} q^{\prime} A_{q^{\prime}}(-1)^{q^{\prime}} \Psi\left(q^{\prime} \pi \varphi\right) \\
& \times\left\{\Lambda_{1}\left(q, q^{\prime}\right)+\left(16 \varphi^{4} / \pi^{2}\right) \Lambda_{3}\left(q, q^{\prime}\right)+\left(16 \varphi^{4} / \pi^{2}\right)^{2} \Lambda_{5}\left(q, q^{\prime}\right)+\cdots\right\} \\
\beta_{p} & =-\frac{4 \varphi p^{2}(-1)^{p}}{(\lambda+\mu) \pi \tau(p \pi / \varphi)} \sum_{q} q A_{q}(-1)^{q} \Psi(q \pi \varphi) \\
& \times\left\{\Lambda_{0}(p, q)+\left(16 \varphi^{4} / \pi^{2}\right) \Lambda_{2}(p, q)+\left(16 \varphi^{4} / \pi^{2}\right)^{2} \Lambda_{4}(p, q)+\cdots\right\}
\end{aligned}
$$

To simplify the expressions, the following abbreviations are introduced

$$
\tau(x)=E(x)+x / e(x) \quad i \quad \Psi(x)=e(x) / \tau(x)
$$

while $\Lambda$ are dimensionless functions of form:

$$
\begin{aligned}
& \Lambda_{0}(p, q)=\frac{1}{\left(p^{2}+\phi^{2} q^{2}\right)^{2}} \\
& \Lambda_{1}\left(q, q^{\prime}\right)=\sum_{p} \frac{p^{3} \Psi(p \pi / \phi)}{\left(p^{2}+\phi^{2} q^{\prime 2}\right)^{2}} \Lambda_{0}(p, q)
\end{aligned}
$$

$\Lambda_{2}(p, q)=\sum_{q^{\prime}} \frac{q^{\prime 3} \Psi\left(q^{\prime} \pi \phi\right)}{\left(p^{2}+\phi^{2} q^{\prime 2}\right)^{2}} \Lambda_{1}\left(q, q^{\prime}\right)$

$\Lambda_{3}\left(q, q^{\prime}\right)=\sum_{p} \frac{p^{3} \Psi(p \pi / \phi)}{\left(p^{2}+\phi^{2} q^{\prime 2}\right)^{2}} \Lambda_{2}(p, q)$

$\Lambda_{4}(p, q)=\sum_{q^{\prime}} \frac{q^{\prime 3} \Psi\left(q^{\prime} \pi \phi\right)}{\left(p^{2}+\phi^{2} q^{\prime 2}\right)^{2}} \Lambda_{3}\left(q, q^{\prime}\right)$

Expressions for displacements, but only as the functions of coordinates $x$ and $y$, are obtained from the expression (7) as follows:

$$
\begin{aligned}
u= & B_{0} x+\sum_{n} B_{n}\left[\left(\frac{\alpha}{2 n}+\frac{a}{4 \varepsilon} \frac{E\left(\frac{1}{2} n a\right)}{e\left(\frac{1}{2} n a\right)}\right) e(n x)-\frac{x E(n x)}{2 \varepsilon}\right] \cos n y \\
& +\sum_{m} \beta_{m}\left[\left(\frac{1}{2 m}-\frac{b}{4 \varepsilon} \frac{E\left(\frac{1}{2} m b\right)}{e\left(\frac{1}{2} m b\right)}\right) E(m y)+\frac{y e(m y)}{2 \varepsilon}\right] \sin m x \\
v & =\beta_{0} y+\sum_{n} B_{n}\left[\left(\frac{1}{2 n}-\frac{a}{4 \varepsilon} \frac{E\left(\frac{1}{2} n a\right)}{e\left(\frac{1}{2} n a\right)}\right) E(n x)+\frac{x e(n x)}{2 \varepsilon}\right] \sin n y \\
& +\sum_{m} \beta_{m}\left[\left(\frac{\alpha}{2 m}+\frac{b}{4 \varepsilon} \frac{E\left(\frac{1}{2} m b\right)}{e\left(\frac{1}{2} m b\right)}\right) e(m y)-\frac{y E(m y)}{2 \varepsilon}\right] \cos m x
\end{aligned}
$$

Expressions for the exact stress functions, for the case of the load under study (DEA), are obtained in accordance with expressions (8):

$$
\begin{aligned}
& N_{1}=A_{0}+(\lambda+\mu) \sum_{n} B_{n}\left[\left(1+\frac{n a}{2} \frac{E\left(\frac{1}{2} n a\right)}{e\left(\frac{1}{2} n a\right)}\right) E(n x)-n x e(n x)\right] \cos n y \\
&+(\lambda+\mu) \sum_{m} \beta_{m}\left[\left(1-\frac{m b}{2} \frac{E\left(\frac{1}{2} m b\right)}{e\left(\frac{1}{2} m b\right)}\right) E(m y)+m y e(m y)\right] \cos m x \\
& N_{2}=(\lambda+\mu) \sum_{n} B_{n}\left[\left(1-\frac{n a}{2} \frac{E\left(\frac{1}{2} n a\right)}{e\left(\frac{1}{2} n a\right)}\right) E(n x)+n x e(n x)\right] \cos n y \\
&+(\lambda+\mu) \sum_{m} \beta_{m}\left[\left(1+\frac{m b}{2} \frac{E\left(\frac{1}{2} m b\right)}{e\left(\frac{1}{2} m b\right)}\right) E(m y)-m y e(m y)\right] \cos m x
\end{aligned}
$$

$$
\begin{aligned}
T_{3}= & (\lambda+\mu) \sum_{n} B_{n}\left(-\frac{n a}{2} \frac{E\left(\frac{1}{2} n a\right)}{e\left(\frac{1}{2} n a\right)} e(n x)+n x E(n x)\right) \sin n y \\
& +(\lambda+\mu) \sum_{m} \beta_{m}\left(-\frac{m b}{2} \frac{E\left(\frac{1}{2} m b\right)}{e\left(\frac{1}{2} m b\right)} e(m y)+m y E(m y)\right) \sin m x
\end{aligned}
$$

And finally, to present the solution in form of a table, stress distributions obtained analytically and using the programs FINEL and ANSYS (based on the finite-element method) are presented side by side in Table 1.

The presented diagrams show that the stress distribution at points subjected to load can hardly be considered uniform, which used to be the most frequent assumption, and also the biggest error, in the analysis of similar problems as made prior to the introduction of exact solutions.

\section{Formulation of stability problem}

The problem of elastic stability of rectangular plates, of various boundary conditions, is considered using the Ritz energy procedure, 
Table 1. Stress distribution within the plate, defined by analytical procedure and by computation

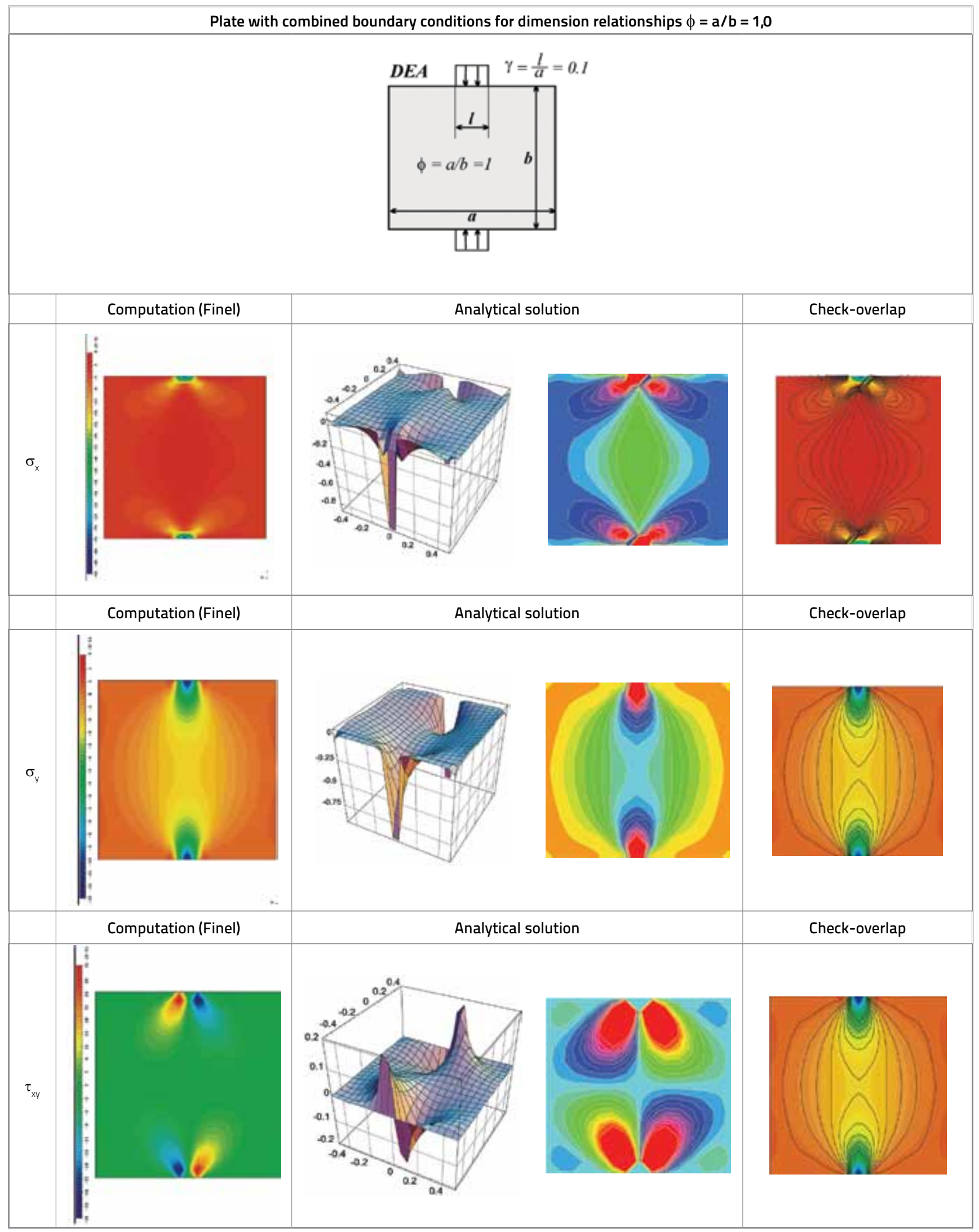


in the scope of which the energy of deformation of a bent plate is defined in a traditional way, while the real stress distribution from the Mathieu's theory of elasticity is introduced during determination of the external force action. Elastic buckling coefficients can be defined very accurately using the exact distribution of stress for any arbitrary external load, and double Fourier series for adequate description of appropriate forms of buckling. The analytic procedure is presented using as example four different types of plates of mixed boundary conditions (SSSS, SCSC, CSCS and CCCC) under a variable compressive stress (DEA). Of course, adequate programs, based on the finite-element method (FINEL and ANSYS), are used for checking the buckling coefficients, as no similar analytical solutions have so far been presented in literature.

\subsection{Buckling functions adopted in the analysis}

For the selected plateand load examples (Figures 3 to 6), we haveadopted deflection functions in form of a double Fourier series (19-22) by which we can meet, member by member, the selected boundary conditions, and which have been proven to approximate the deformed configuration quite well, for a very wide spectrum of plate dimension relationships.

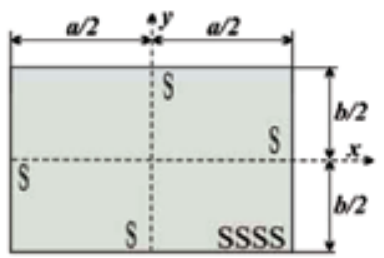

\section{Example 1}

edges $x= \pm a / 2$ simply supported (S) edges $y= \pm b / 2$ simply supported (S)

Figure 3. Simply supported plate (Example 1:SSSS)

$w=\sum_{m=1}^{s} \sum_{n=1}^{s} W_{m n} \sin \frac{m \pi}{a}\left(x+\frac{a}{2}\right) \sin \frac{n \pi}{b}\left(y+\frac{b}{2}\right)$

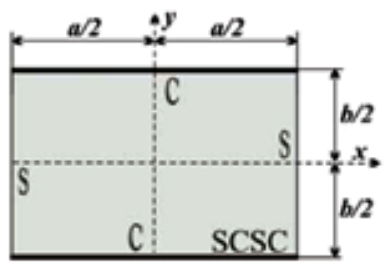

\section{Example 2}

edges $x= \pm a / 2$ simply supported (S)

edges $y= \pm b / 2$ simply constrained (S)

Figure 4. Plate with combined boundary conditions (Example 2:SCSC)

$w=\sum_{m=1}^{s} \sum_{n=1}^{s} W_{m n} \sin \frac{m \pi}{a}\left(x+\frac{a}{2}\right)\left(\cos \frac{(n-1) \pi}{b}\left(y+\frac{b}{2}\right)-\cos \frac{(n+1) \pi}{b}\left(y+\frac{b}{2}\right)\right)$

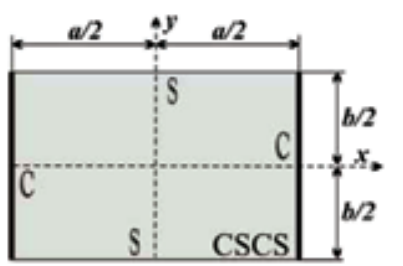

Example 3

edges $x= \pm a / 2$ constrained (S)

edges $y= \pm b / 2$ simply supported (S)

Figure 5. Plate with combined boundary conditions (Example 3:SCSC)

$W=\sum_{m=1}^{s} \sum_{n=1}^{s} W_{m n}\left(\cos \frac{(m-1) \pi}{a}\left(x+\frac{a}{2}\right)-\cos \frac{(m+1) \pi}{a}\left(x+\frac{a}{2}\right)\right) \sin \frac{n \pi}{b}\left(y+\frac{b}{2}\right)$

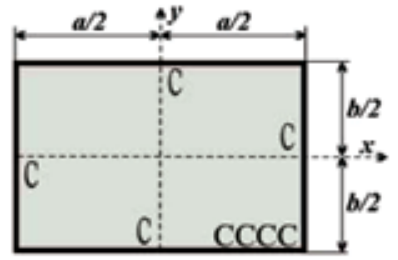

Example 4

edges $x= \pm a / 2$ constrained (S)

edges $y= \pm b / 2$ constrained (S)

Figure 6. Constrained plate (Example 4:CCCC)

$$
\begin{gathered}
w=\sum_{m=1}^{s} \sum_{n=1}^{s} W_{m n}\left(\cos \frac{(m-1) \pi}{a}\left(x+\frac{a}{2}\right)-\cos \frac{(m+1) \pi}{a}\left(x+\frac{a}{2}\right)\right) . \\
\left(\cos \frac{(n-1) \pi}{b}\left(y+\frac{b}{2}\right)-\cos \frac{(n+1) \pi}{b}\left(y+\frac{b}{2}\right)\right)
\end{gathered}
$$

\subsection{Plate bending strain energy}

When defining the total potential energy of a system in the scope of the Ritz energy procedure, the first step is to define strain energy at plate bending, and this in a usual traditional way:

$U=\frac{1}{2} D \int_{-a / 2}^{a / 2} \int_{-b / 2}^{b / 2}\left[\left(\frac{\partial^{2} w}{\partial x^{2}}+\frac{\partial^{2} w}{\partial y^{2}}\right)^{2}-2(1-v)\left[\frac{\partial^{2} w}{\partial x^{2}} \frac{\partial^{2} w}{\partial y^{2}}-\left(\frac{\partial^{2} w}{\partial x \partial y}\right)^{2}\right]\right] d x d y$

where $D$ is flexural stiffness.

\subsection{Action of external forces}

The part of the system's potential energy that is related to the action of external forces is represented by the expression (24), which now contains designations of the exact stress distribution $N_{1^{\prime}} N_{2^{\prime}}$ and $T_{3}$ from the Mathieu's theory of elasticity (18):

$$
V=-\frac{t}{2} \int_{-a / 2}^{a / 2} \int_{-b / 2}^{b / 2}\left[N_{1}\left(\frac{\partial w}{\partial x}\right)^{2}+N_{2}\left(\frac{\partial w}{\partial y}\right)^{2}+2 T_{3} \frac{\partial w}{\partial x} \frac{\partial w}{\partial y}\right] d x d y
$$

Therefore, by introducing the exact stress functions the expression which takes into account the action of external forces becomes much more complicated. This is the fundamental difference when compared to other stability analyses where plates are not exclusively simply supported along all edges. In order to simplify the computer program burdened by the presence of many integrals containing various combinations of hyperbolic and trigonometric functions, included in deflection and stress functions, it was indispensable to simply the expression (24) and consider contribution of individual members (25, 25a, 25b, 25c):

$V=V_{1}+V_{2}+V_{3}$

where:

$V_{1}=-\frac{t}{2} \int_{-a / 2}^{a / 2} \int_{-b / 2}^{b / 2} N_{1}\left(\frac{\partial w}{\partial x}\right)^{2} d x d y$

$V_{2}=-\frac{t}{2} \int_{-a / 2}^{a / 2} \int_{-b / 2}^{b / 2} N_{2}\left(\frac{\partial w}{\partial y}\right)^{2} d x d y$ 


$$
V_{3}=-t \int_{-a / 2}^{a / 2} \int_{-b / 2}^{b / 2} T_{3} \frac{\partial w}{\partial x} \frac{\partial w}{\partial y} d x d y
$$

\subsection{Reduction to the problem of eigenvalues}

After definition of the plate-bending strain energy, $U$, and the external force action, $V$, the total potential energy of the system can be written as follows:

$\Pi=U+V$

The condition (27) is obtained from the principle of minimum potential energy:

$\frac{\partial \Pi}{\partial W_{m n}}=\frac{\partial U}{\partial W_{m n}}+\frac{\partial V}{\partial W_{m n}}$

which can in principle be reduced to the system of $\mathrm{m} \cdot \mathrm{n}$ homogeneous linear equations according to unknown coefficients $W_{m n}$. The existence of nontrivial solution, i.e. of the requirement that the determinant of the system is equal to zero, is reduced to the traditional problem of eigenvalues, in the scope of which only the lowest eigenvalue is of practical significance to us, and it represents the critical load we are looking for. Of course, due to extensiveness of the procedure for approximation of stress and deflection functions, which is directly dependent on the number of members in the series, the use of an appropriate computer program (MATHEMATICA) is considered indispensable.

Table 2. Buckling coefficient values for "SSSS" plate

\section{Examples and results}

As already indicated, in order to prove usability of the analytical procedure used in the paper to solve elastic stability problems, four different plate types: SSSS, SCSC, CSCS and CCCC (Figures 3 to 6), are considered. They are influenced by locally distributed stresses (DEA), for which no analytical results exist in the literature (Figure 7). All results for different dimension relationships $(\phi=0,3-2,0)$, and for the influence of the local compressive stress $(\gamma=0,0-1,0)$, are presented tabularly (Tables 2 to 5). In addition to buckling coefficients obtained by the derived analytical procedure, they also include calculation results obtained using the FINEL and ANSYS software, based on the finite-element method.

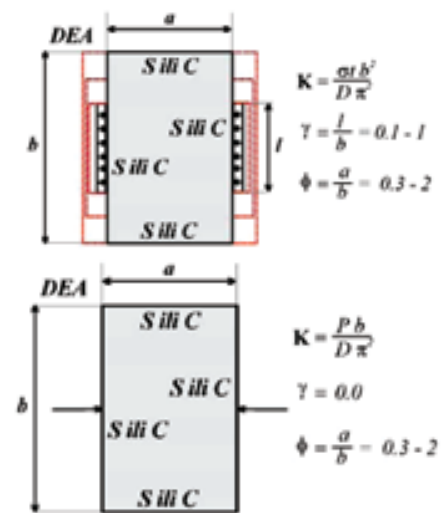

Figure 7. Analysed example

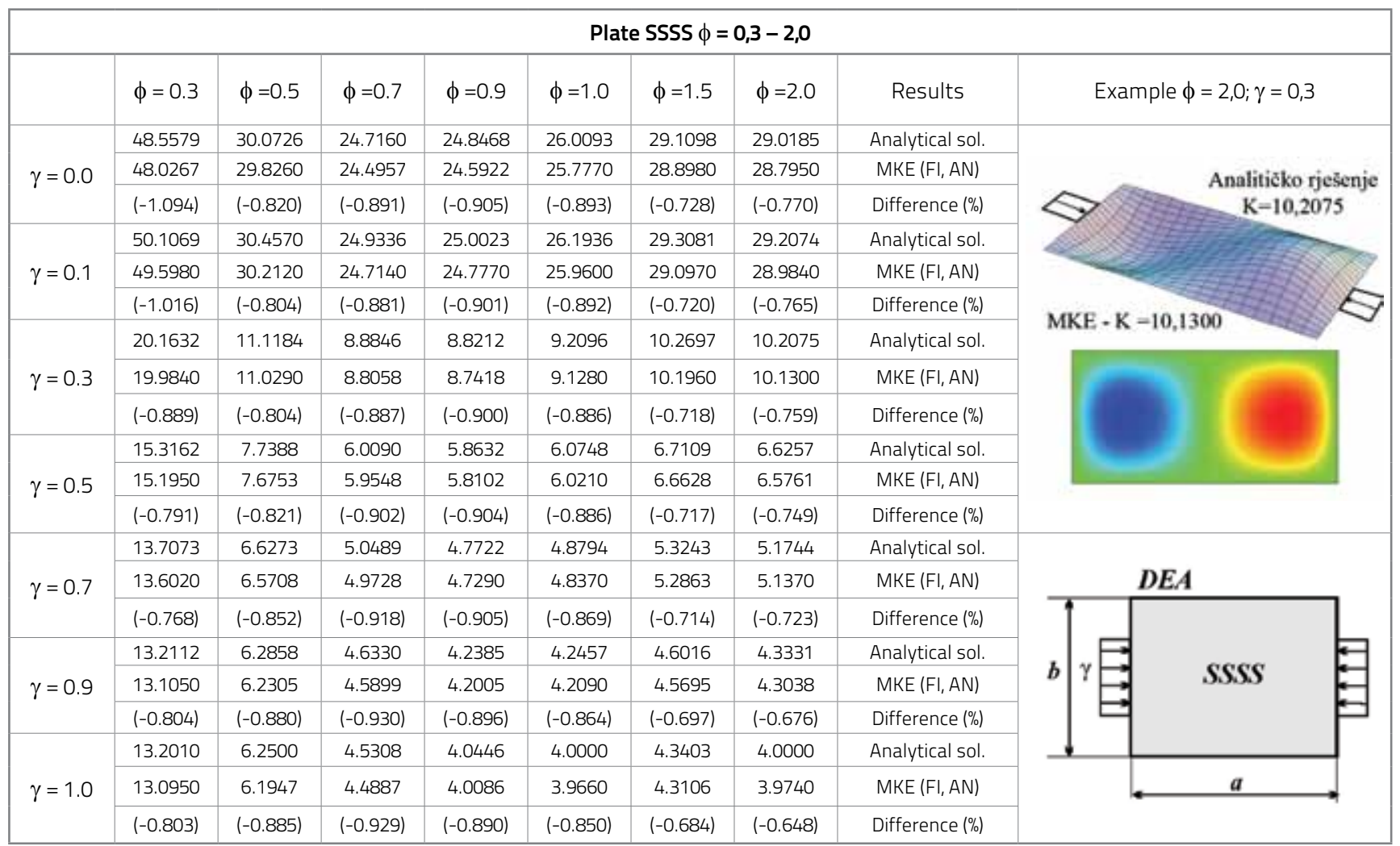


Table 3. Buckling coefficient values for slabs SCSC and CSCS

\begin{tabular}{|c|c|c|c|c|c|c|c|c|c|}
\hline \multicolumn{10}{|c|}{ Plate SCSC $\phi=0.3-2,0$} \\
\hline & $\phi=0.3$ & $\phi=0.5$ & $\phi=0.7$ & $\phi=0.9$ & $\phi=1.0$ & $\phi=1.5$ & $\phi=2.0$ & Results & Example $\phi=2,0 ; \gamma=0,3$ \\
\hline \multirow{3}{*}{$\gamma=0.0$} & 48.7433 & 33.1740 & 34.0400 & 41.1378 & 39.4680 & 40.6440 & 41.0340 & Analytical sol. & \\
\hline & 48.6300 & 33.1200 & 33.9914 & 41.0900 & 39.4210 & 40.4030 & 40.7920 & $\operatorname{MKE}(\mathrm{Fl}, \mathrm{AN})$ & \\
\hline & $(-0.232)$ & $(-0.163)$ & $(-0.143)$ & $(-0.116)$ & $(-0.119)$ & $(-0.593)$ & $(-0.590)$ & Difference (\%) & \\
\hline \multirow{3}{*}{$\gamma=0.1$} & 50.3111 & 33.6731 & 34.4509 & 41.6785 & 39.9466 & 41.1357 & 41.5313 & Analytical sol. & \\
\hline & 50.2000 & 33.6200 & 34.2360 & 41.4510 & 39.7330 & 40.9010 & 41.2960 & MKE (FI, AN) & \\
\hline & $(-0.221)$ & $(-0.158)$ & $(-0.624)$ & $(-0.546)$ & $(-0.535)$ & $(-0.571)$ & $(-0.567)$ & Difference (\%) & \\
\hline \multirow{3}{*}{$\gamma=0.3$} & 20.3074 & 12.4985 & 12.5559 & 15.2077 & 14.4908 & 14.9050 & 15.0397 & Analytical sol. & \\
\hline & 20.2667 & 12.4800 & 12.4800 & 15.1310 & 14.4190 & 14.8270 & 14.9620 & MKE (FI, AN) & ) \\
\hline & $(-0.201)$ & $(-0.148)$ & $(-0.604)$ & $(-0.504)$ & $(-0.495)$ & $(-0.523)$ & $(-0.517)$ & Difference (\%) & \\
\hline \multirow{3}{*}{$\gamma=0.5$} & 15.5533 & 8.9588 & 8.7929 & 10.5539 & 9.9820 & 10.2147 & 10.2723 & Analytical sol. & \\
\hline & 15.5267 & 8.9456 & 8.7414 & 10.5030 & 9.9347 & 10.1650 & 10.2240 & MKE (FI, AN) & \\
\hline & $(-0.171)$ & $(-0.147)$ & $(-0.586)$ & $(-0.482)$ & $(-0.474)$ & $(-0.486)$ & $(-0.470)$ & Difference (\%) & \\
\hline \multirow{3}{*}{$\gamma=0.7$} & 14.1556 & 7.9297 & 7.5893 & 8.9950 & 8.4330 & 8.4768 & 8.4607 & Analytical sol. & \\
\hline & 14.1317 & 7.9177 & 7.5457 & 8.9526 & 8.3942 & 8.4396 & 8.4253 & MKE (FI, AN) & \\
\hline & $(-0.168)$ & $(-0.151)$ & $(-0.574)$ & $(-0.472)$ & $(-0.460)$ & $(-0.439)$ & $(-0.418)$ & Difference $(\%)$ & $A$ \\
\hline \multirow{3}{*}{$\gamma=0.9$} & 13.8716 & 7.6874 & 7.1305 & 8.2673 & 7.8284 & 7.5142 & 7.4138 & Analytical sol. & \\
\hline & 13.8481 & 7.6756 & 7.0897 & 8.2300 & 7.7928 & 7.4854 & 7.3876 & MKE (FI, AN) & $s c$ \\
\hline & $(-0.169)$ & $(-0.153)$ & $(-0.572)$ & $(-0.451)$ & $(-0.455)$ & $(-0.383)$ & $(-0.353)$ & Difference (\%) & \\
\hline \multirow{3}{*}{$\gamma=1.0$} & 13.9044 & 7.6927 & 7.0021 & 7.8583 & 7.6927 & 7.1172 & 6.9729 & Analytical sol. & \\
\hline & 13.8822 & 7.6812 & 6.9624 & 7.8234 & 7.6586 & 7.0923 & 6.9511 & MKE (FI, AN) & \\
\hline & $(-0.160)$ & $(-0.149)$ & $(-0.567)$ & $(-0.438)$ & $(-0.443)$ & $(-0.350)$ & $(-0.312)$ & Difference (\%) & \\
\hline 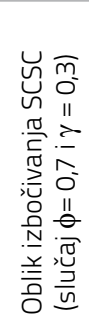 & \multicolumn{4}{|c|}{$\begin{array}{l}\text { MKE - FINEL } \\
(K=12.4800)\end{array}$} & \multicolumn{3}{|c|}{$\begin{array}{l}\text { MKE - ANSYS } \\
(K=12.5401)\end{array}$} & \multicolumn{2}{|c|}{ Analytical solution $(K=12.5559)$} \\
\hline \multicolumn{10}{|c|}{ Plate $\operatorname{CSCS} \phi=0.3-2,0$} \\
\hline & $\phi=0.3$ & $\phi=0.5$ & $\phi=0.7$ & $\phi=0.9$ & $\phi=1.0$ & $\phi=1.5$ & $\phi=2.0$ & Results & 2,$0 ; \gamma=0,3$ \\
\hline \multirow{3}{*}{$\gamma=0.0$} & 136.527 & 81.3980 & 58.0843 & 48.8844 & 47.3130 & 47.6780 & 43.952 & Analytical sol. & \multirow{12}{*}{ 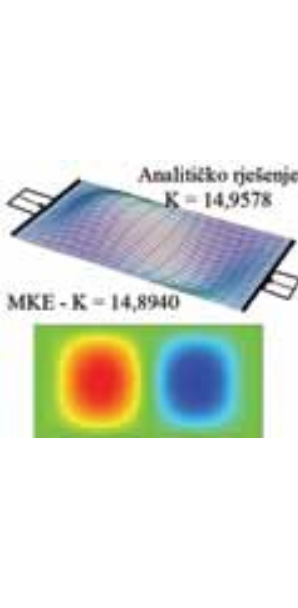 } \\
\hline & 136.390 & 81.3460 & 58.0414 & 48.8433 & 47.2680 & 47.4730 & 43.741 & $\operatorname{MKE}(\mathrm{Fl}, \mathrm{AN})$ & \\
\hline & $(-0.100)$ & $(-0.064)$ & $(-0.074)$ & $(-0.084)$ & $(-0.095)$ & $(-0.430)$ & $(-0.480)$ & Difference (\%) & \\
\hline \multirow{3}{*}{$\gamma=0.1$} & 143.156 & 82.9067 & 58.6814 & 49.2515 & 47.6257 & 47.8902 & 44.0682 & Analytical sol. & \\
\hline & 143.111 & 82.8760 & 58.4730 & 49.0760 & 47.4510 & 47.6950 & 43.8630 & $\operatorname{MKE}(\mathrm{Fl}, \mathrm{AN})$ & \\
\hline & $(-0.031)$ & $(-0.037)$ & $(-0.355)$ & $(-0.356)$ & $(-0.367)$ & $(-0.408)$ & $(-0.466)$ & Difference (\%) & \\
\hline \multirow{3}{*}{$\gamma=0.3$} & 61.9592 & 30.9996 & 20.9747 & 17.3066 & 16.6288 & 16.4781 & 14.9578 & Analytical sol. & \\
\hline & 61.9370 & 30.9907 & 20.9060 & 17.2480 & 16.5710 & 16.4160 & 14.8940 & $\operatorname{MKE}(\mathrm{Fl}, \mathrm{AN})$ & \\
\hline & $(-0.036)$ & $(-0.029)$ & $(-0.328)$ & $(-0.339)$ & $(-0.347)$ & $(-0.377)$ & $(-0.426)$ & Difference (\%) & \\
\hline \multirow{3}{*}{$\gamma=0.5$} & 50.7689 & 22.0930 & 14.1475 & 11.3570 & 10.7786 & 10.4280 & 9.2197 & Analytical sol. & \\
\hline & 50.7511 & 22.0864 & 14.1010 & 11.3190 & 10.7420 & 10.3900 & 9.1821 & MKE (FI, AN) & \\
\hline & $(-0.035)$ & $(-0.030)$ & $(-0.329)$ & $(-0.335)$ & $(-0.340)$ & $(-0.364)$ & $(-0.408)$ & Difference $(\%)$ & \\
\hline
\end{tabular}


Table 3. - continuation - Buckling coefficient values for slabs CSCS

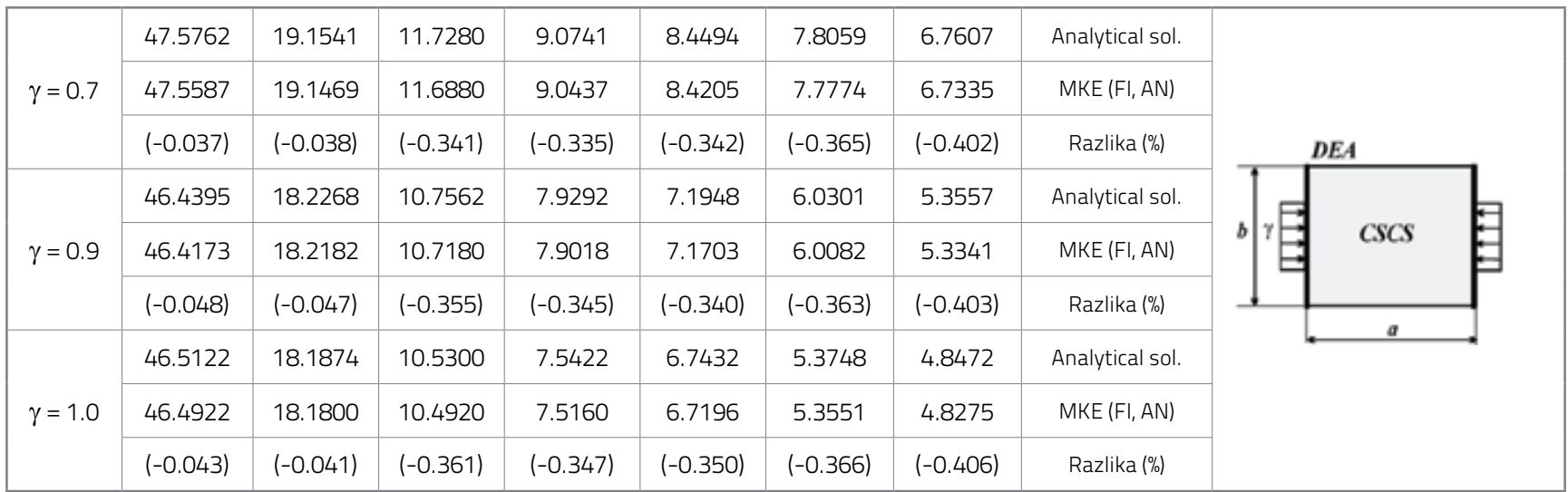

Table 4. Buckling coefficient values for "CCCC" plate

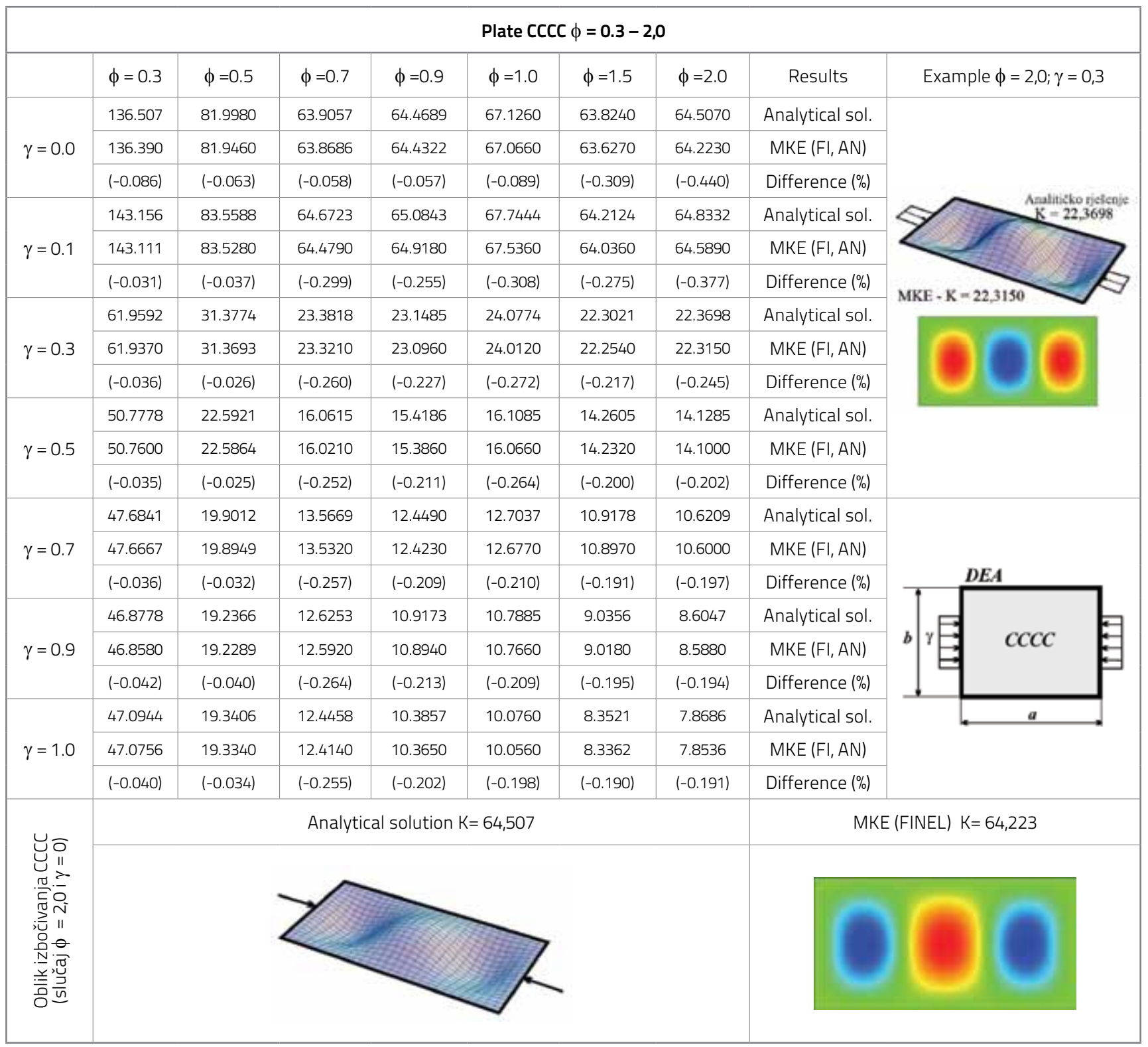


To enable proper evaluation of the analytical solutions presented in the paper, it is important to take note of some limitations that had to be introduced for practical reasons. In fact, buckling coefficients presented in the tables were obtained by introducing 20 members for the deflection function series, and 60 members for the stress function series. For stress functions, an absolute stability of the solution is obtained with 40 or more members, while in case of deflection functions even more members would sometimes be needed, depending on boundary conditions and load. By limiting the number of members, we have obtained the solution that is somewhat higher than the exact solution which would, of course, be attainable if we were able to introduce an infinite number of members. However, due to extreme complexity of the procedure, and great number of integrals to be solved, the analysis was made with 20 members of the deflection function series, for all plate dimensions and boundary conditions, using the above mentioned normal load. After a detailed analysis of the results, the accuracy of assumptions was realistically evaluated, and this not only for the Ritz method, but also for the design parameters included in the method, which directly influence both convergence and level of accuracy of the solution.

\section{Conclusion}

After a detailed analysis of results (Tables 2 to 5), it can easily be noted that the analytical solution manifests a good behaviour in the studied range of plate dimensions $(\phi=0.3-2.0)$ and load $(\gamma=0.0-1.0)$. Buckling coefficient values for four selected plate types (SSSS, SCSC, CSCS and CCCC) under locally distributed compressive stress, show maximum deviation with respect to values gained using the finite-element method of no more than 1.0 percent (SSSS $\phi=0.3$ and $\gamma=0.0$ ). Nevertheless, this difference should be taken as relative because, for the same example, and using the ANSYS program, the value obtained $(K=$ 48.482) deviates by only 0.16 percent from the analytical solution. In other words, solutions obtained by the finiteelement method (FINEL, ANSYS) depend on the network density and on the adopted type of final element, and have their limitations as to the level of accuracy. This is also true for the analytical procedure presented in this paper, due to limited number of members in the series. Finally, it can be concluded that the number of members in the series of deflection and stress functions is sufficient for the analysed cases of plates with mixed boundary conditions, subjected to variable compressive load. Obviously, in cases with more complex types of load, which were also subjected to detailed verification, it is indispensable to pay special attention to proper selection of the type and number of members in the series, and to stress and deflection functions, which undoubtedly directly influences the level of accuracy of solutions, although not the applicability of the analytical procedure presented in the paper.

\section{REFERENCES}

[1] Mathieu, E.: Theorie de l'elasticite des corps solides, Seconde partie. GauthierᄀVillars, Paris, 1890.

[2] Baker, G. \& Pavlović, M. N.: Elastic stability of simply supported rectangular plates under locally distributed edge forces, Journal of Applied Mechanics 104, pp. 177-179, 1982.

[3] Baker, G. \& Pavlović, M. N.: Rectangular plates compressed by series of in-plane loads: stability and stress distribution, The Aeronautical Journal 87, pp. 183-188, 1983.

[4] Pavlović, M. N. \& Baker, G.: Buckling of non-uniformly compressed plates. Theo.\& Appl.Mech., Trans.Yugosl.Soc.Mech., vol. 9, pp. 91-104, 1983

[5] Baker, G. \& Pavlović, M. N.: Stability of wide strips under locally distributed forces, Journal of Applied Mechanics 107, pp. 232234,1985

[6] Baker, G., Pavlović, M. N. \& Tahan, N.: An exact solution to the two-dimensional elasticity problem with rectangular boundaries under arbitrary edge forces, Phil. Trans. R. Soc. London, A 393, pp. 307-336, 1993.

[7] Liu, Y. G.: Buckling of Plates under Non-Uniform Stresses, with Particular Emphasis on Shear, Ph. D Thesis, Imperial College, London, 2006.

[8] Mijušković, O.: Analiza stabilnosti pravougaonih ploča korišćenjem tačne funkcije napona, doktorska disertacija, Građevinski fakultet, Beograd, 2008. 